\title{
Cuando el mármol vive... La potencia peronista en un recorrido biográfico de las esculturas del Monumento al Descamisado
}

\author{
[When the Marble lives... \\ The Peronist Power in a Biographical Tour of the Sculptures \\ of the Monumento al Descamisado] \\ María Florencia Reyes Santiago \\ (Universidad de Buenos Aires, Argentina) \\ florenciareyes@yahoo.com.ar
}

\begin{abstract}
Resumen
Este artículo se propone pensar la potencia pretérita y actual- del peronismo, como movimiento político-cultural, a partir de un análisis de las esculturas tituladas Los derechos del trabajador y La razón de mi vida, pensadas originalmente como parte del llamado Monumento al Descamisado, diseñado por el gobierno en 1951, y que actualmente forman parte del patrimonio del Museo Histórico 17 de octubre, ubicado en la localidad de San Vicente, provincia de Buenos Aires. Abordándolas desde el punto de vista del enfoque biográfico de la cultura material, se realiza un recorrido de los distintos momentos que atravesaron las esculturas hasta el lugar (físico, histórico y simbólico) que ocupan hoy, entendiendo así que no solo han logrado trascender enormemente a sus creadores, sino que además se han visto resignificadas y transformadas en diversas instancias, producto de cambiantes relaciones sociales y de poder.
\end{abstract}

Palabras claves: Monumento al Descamisado; Peronismo; Biografía de los objetos; Resignificaciones.

\begin{abstract}
This article intends to think about the power -past and present- of Peronism as a political-cultural movement, based on an analysis of the sculptures entitled Los derechos del trabajador and La razón de mi vida, originally intended as part of the so-called Monumento al Descamisado, designed by the government in 1951, and currently part of the heritage of the Museo Histórico 17 de octubre, located in the town of San Vicente, Province of Buenos Aires. Addressing them from the point of view of the biographical approach of the material culture, a tour of the different moments that the sculptures went through to the place (physical, historical and symbolic) that they occupy today is realized, thus understanding not only that they have managed to transcend enormously to its creators, but have also been resignified and transformed into various instances, as the product of changing social and power relations.
\end{abstract}

Keywords: Monumento al Descamisado; Peronism; Biography of Objects; Resignifications.

Recibido: $13 / 01 / 2020$

Evaluación: $15 / 07 / 2020$

Aceptado: 05/10/2020

Anuario de la Escuela de Historia Virtual - Año 11 - N 18 - 2020: pp. 188-207.

ISSN: 1853-7049

http://revistas.unc.edu.ar/index.php/anuariohistoria 


\section{Cuando el mármol vive... La potencia peronista en un recorrido biográfico de las esculturas del Monumento al Descamisado}

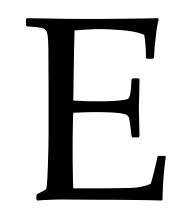

ste artículo se propone pensar la potencia - pretérita y actual- del peronismo como movimiento político-cultural, a partir de un análisis de las esculturas tituladas Los derechos del trabajador y La razón de mi vida, que forman parte del patrimonio del Museo Histórico 17 de octubre, ubicado en la localidad de San Vicente, Provincia de Buenos Aires (Figura 1). Pensadas originalmente como parte del llamado Monumento al Descamisado, diseñado en 1951, durante el el primer gobierno peronista, fueron primero rastreadas por distintos grupos de tareas del gobierno de facto que derrocó a aquel en 1955 y, luego, junto a hordas de seguidores de ese golpe de Estado, decapitadas, mutiladas y arrojadas al Riachuelo, donde permanecieron casi treinta años, para finalmente ser recuperadas y trasladadas al Museo donde son exhibidas hoy. 


\section{Figura 1}

Esculturas Los derechos del trabajador y La razón de mi vida

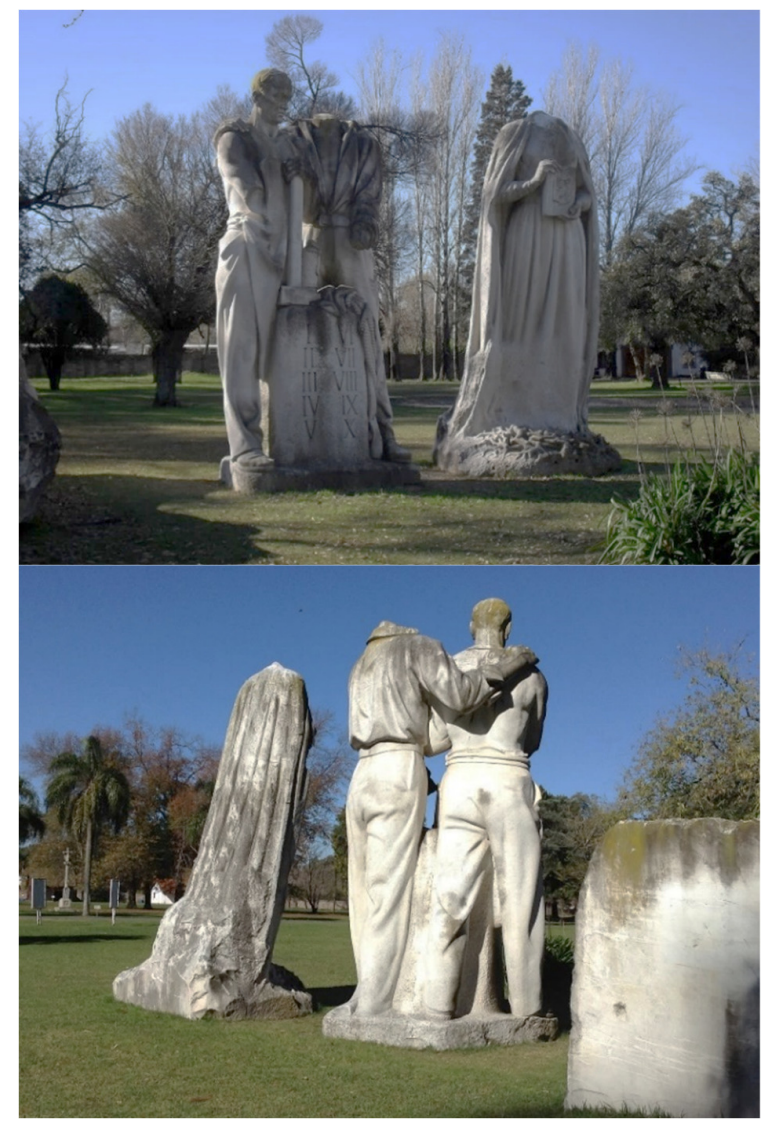

Fuente: Museo Histórico 17 de octubre, San Vicente, Buenos Aires. Fuente: http://viajealasestatuas.blogspot.com.ar/p/estudio-preliminar-por-oscarandres-de.html

(Fecha de consulta: 20/04/2019)

Para ello, se abordan estas esculturas desde el enfoque biográfico de la cultura material, considerando que se trata de objetos que han trascendido enormemente a sus creadores, atravesando diversas instancias de resignificaciones hasta su actual anclaje. Se parte, entonces, de una definición de la cultura material que no solamente la entiende como el cúmulo de objetos, bienes, herramientas o artefactos fabricados, usados o seleccionados por un grupo humano para diversas tareas, sino que incluye además "las prácticas sociales cotidianas de las que tales objetos formaban parte y los diferentes significados que lo material adquiere en esta mutua interacción entre los hombres y los objetos" (Moreyra, 2011, p. 122). Por otra parte, al tratarse de esculturas que fueron recuperadas/rescatadas, luego de haber sido destruidas y descartadas, y que se presentan como "piezas, vestigios o indicios" de una totalidad mayor, puede entendérselas como "registro arqueo-lógico", en términos de Criado Boado (2012, p. 190), en tanto son afectadas por instancias "pretéritas (la formación social original y las que, 
posteriormente, han reutilizado y revalorizado el registro), ambientales (los procesos postdeposicionales naturales) y actuales (el complejo socioinstitucional en el que se significa y valoriza el registro)".

Así, este artículo propone un recorrido de los distintos momentos que atravesaron las esculturas hasta el lugar (físico, histórico y simbólico) que ocupan hoy. Para ello, se describen las diversas significaciones y valores simbólicos que adquirieron en cada una de ellas, pensando "su recategorización [y] el cambio en su funcionalidad, ya sea en un mismo contexto cultural o como consecuencia de un periplo más o menos largo tanto en el espacio como en el tiempo" (Carreras Monfort y Nadal Lorenzo, 2002-2003, p. 75). Finalmente, el trabajo estudia también las relaciones sociales y de poder que esas resignificaciones expresan y sus consecuentes transformaciones.

\section{Creación y destrucción (o instancia pretérita) ${ }^{1}$}

Siguiendo las categorías básicas de la evidencia arqueológica propuestas por Renfrew y Bahn (1993, p. 52), las esculturas Los derechos del trabajador y La razón de mi vida son estructuras simples, es decir, artefactos no portátiles, que "pueden proporcionar información sobre estructuras más complejas o construcciones, definidas como edificaciones de todo tipo". En su origen, fueron pensadas como parte de un complejo escultórico mayor, encargado por el primer gobierno peronista al escultor italiano Leone Tommasi, en el año 1951. Formaban parte de lo que iba a ser el Monumento al Descamisado, que, en palabras de Perón:

deb[ía] ser simple y (...) estar representado el pueblo en su concepción a través de las distintas épocas de nuestra historia. Su figura central debe ser la del descamisado que todos conocemos y vemos en la calle; la del descamisado que vimos el 17 de octubre. ${ }^{2}$

En efecto, el monumento estaba constituido principalmente por un gran coloso de 67 metros de altura, que representaba al hombre de trabajo que el peronismo buscaba identificar como la principal base social de su movimiento. Con una postura firme, un gesto adusto, la mirada al frente, su camisa abierta, mostrando un pecho fuerte y vigoroso, y sus puños cerrados, listos para la defensa de sus derechos recientemente reconocidos por el Estado, este "descamisado" se erigía sobre una columna de igual altura, que en su base presentaba un friso envolvente con

\footnotetext{
${ }^{1}$ La denominación de estas "edades" no sigue el modelo de flujo propuesto por Schiffer (1990, p. 83), en el que "las actividades en las que participan los elementos duraderos (...) pueden dividirse en cinco procesos: obtención («procuramiento»), manufactura, uso, mantenimiento y desecho". Por el contrario, se persigue titularlas en relación a aquellas instancias definidas por Criado Boado (2012), que atravesaron los objetos aquí estudiados.

2 Discurso de Perón en una ceremonia en su despacho oficial en Casa de Gobierno, donde coloca en posesión de sus funciones a los miembros de la Comisión Nacional Honoraria encargados de los trabajos relativos al monumento. Guía quincenal de la actividad intelectual y artística argentina, año 1, núm. 8, Buenos Aires, Comisión Nacional de Cultura, agosto de 1947, p. 59.
} 
192 | Cuando el mármol vive... La potencia peronista en un recorrido...

bajorrelieves que buscaban narrar el devenir de esa figura. El presidente explicó, en aquel mismo discurso, que el monumento contaría:

la historia (...) desde la colonia, desde el indio encomendero que fue el primer descamisado, hasta la etapa del 17 de octubre (...). Debe tomarse la época de la colonización, donde tenemos al descamisado trabajando la tierra. Luego tomarlo en la independencia, con su caballo luchando por ella. Ahí tenemos al «deshilachado» de Güemes. Después viene la época de la organización nacional. Lo tenemos después en la época constructiva, trabajando en el campo y en la industria, llegando así en nuestros días al actual descamisado. ${ }^{3}$

Completaba el monumento una inmensa base de más de 100 metros de diámetro y 10 de altura, que formaba la entrada al complejo, en la que los visitantes eran recibidos por dieciséis estatuas alegóricas que rodeaban el perímetro, en forma de peristilo circular (Figura 2).

\section{Figura 2}

\section{Maqueta en escala del futuro Monumento al Descamisado con la ubicación de las esculturas}

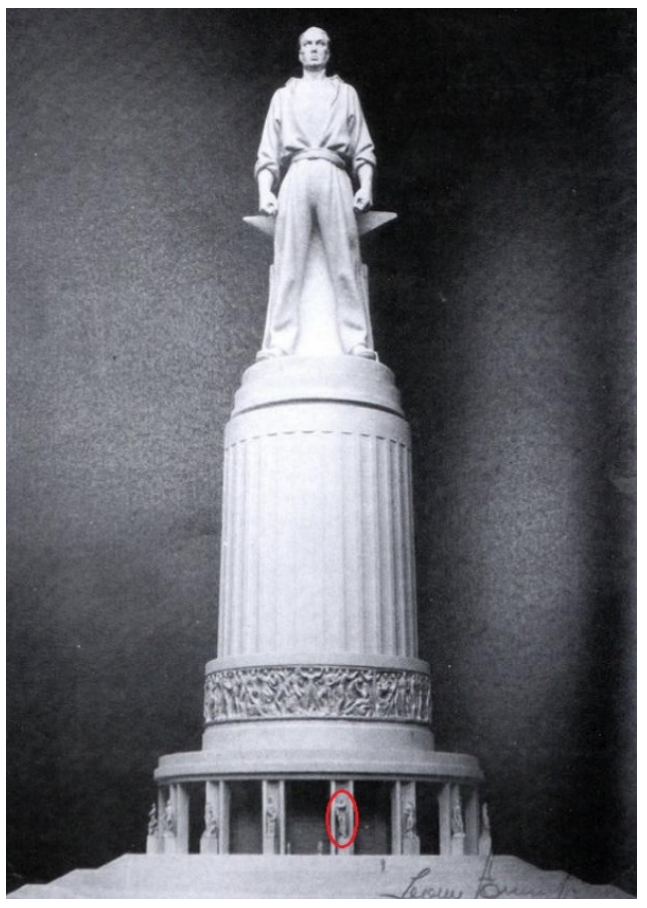

Fuente: Elaboración propia, sobre imagen extraída de https://www.caminosculturales.com.ar/lamuerte-de-evita/

(Fecha de consulta: 12 de mayo de 2019)

${ }^{3}$ Idem. 
De este conjunto eran parte las esculturas analizadas en el presente artículo. Con 4,50 metros de altura y 45 toneladas de peso cada una, estas estatuas de mármol de Carrara ${ }^{4}$ se titulaban Los derechos del trabajador y La razón de mi vida, y eran acompañadas por otras catorce, que representaban distintos "principios peronistas" como la justicia social, los derechos de la ancianidad, la dignificación de la mujer, la soberanía política y la independencia económica, entre otros.

En la primera de ellas, dos hombres se ubican delante de un monolito, que, como las tablas de Moisés, lleva escritos los diez números de los consagrados derechos de los trabajadores. ${ }^{5}$ Uno de ellos viste un overol y, con la mirada baja, porta en su mano izquierda la maza que lo identifica como obrero industrial. Sobre su hombro se apoya el brazo de su acompañante que, vestido como el coloso descamisado principal, mira al frente con más firmeza que su compañero, al que acompaña y sostiene. No casualmente, entonces, esta segunda figura presenta en su rostro rasgos similares a los de Perón. Así era descripta la escultura en el folleto de su presentación original:

Con lo que sueñan los trabajadores del mundo, es esta escultura que lleva en su mano «Los derechos del trabajador». Realidad argentina de la hora presente. Símbolo de una conquista realizada a la sombra de las banderas del Justicialismo. ${ }^{6}$

La segunda escultura, titulada La razón de mi vida, se ocupaba de la otra figura excluyente del movimiento peronista: Evita. Con su clásico rodete y vestida con un manto similar al de las vírgenes, Eva sostiene entre sus manos un ejemplar de aquella autobiografía, que llevaba en su lomo el tradicional escudo peronista. La imagen cristiana del sacrificio se completa con

\footnotetext{
${ }^{4}$ Sobre el material específico de las esculturas, también hizo Perón una referencia en esa ceremonia: “La piedra de granito es lo más triste y opaco para un monumento. El mármol y el bronce es lo único noble para la escultura cuando ella debe representar al hombre con sensación de vida" (Idem). En este sentido, puede considerarse la distinción de Pye, que retoma negativamente Ingold (2013, p. 35), entre propiedades y cualidades de los materiales. Mientras que las primeras pueden observarse objetivamente y medirse, las segundas responden a cuestiones subjetivas, en las que "cada uno tiene su propia visión de lo que [cada material] es". En el caso de las esculturas, Perón diferencia el mármol de la piedra de granito por su carácter "noble", siendo aquel más apropiado para representar "vitalidad". Esa resulta ser una apreciación individual, vinculada a la finalidad buscada para aquellas figuras.

${ }^{5}$ Perón proclamó los “Derechos del Trabajador" el 24 de febrero de 1947, en un acto organizado por la CGT en el Teatro Colón y estos fueron posteriormente formalizados, primero, a través de un decreto del Poder Ejecutivo Nacional, en marzo de 1947, y luego incorporados en el artículo 37 de la nueva Constitución de la Nación Argentina, sancionada por una Convención Constituyente en marzo de 1949. Estos derechos eran: I. Derecho de trabajar; II. Derecho a una retribución justa; III. Derecho a la capacitación; IV. Derecho a condiciones dignas de trabajo; V. Derecho a la preservación de la salud; VI. Derecho al bienestar; VII. Derecho a la seguridad social; VIII. Derecho a la protección de la familia; IX. Derecho al mejoramiento económico y X. Derecho a la defensa de los intereses profesionales. Información extraída del sitio web: Perón vence al tiempo. Recuperado de http://www.peronvencealtiempo.com.ar/peron/textos-de-peron/251-los-derechos-del-trabajador-1-juan-domingoperon-24-de-febrero-de-1947 (Fecha de descarga: 27/03/2019). Sobre "el Líder vuelto Moisés concediendo la ley": Gené (2008, p. 81) afirma que "en su época postrera, el peronismo se consuma como religión política al incorporar elementos religiosos en la sacralización del orden político".

${ }^{6}$ Descripción citada en la revista Mundo Peronista, núm. 47, 5 de agosto de 1953, p. 23.
} 
194 | Cuando el mármol vive... La potencia peronista en un recorrido...

las espinas que, desde sus pies descalzos, trepan al manto, amenazándola con cubrirla completamente. Así definía el folleto la idea primigenia, luego modificada en la escultura final:

Heridos los pies descalzos que se apoyan en el camino de espinas, la resolución, la fe, el fanatismo sagrado de Eva Perón avanzan hacia la gloria inmortal de su destino casi santos; sostiene en una mano «La razón de mi vida» y en la otra levanta la antorcha con la luz de hálito divino que tocó su frente. ${ }^{7}$

Finalmente simplificada, esta escultura no sería la única dedicada a Eva en el monumento. Su muerte, en julio de 1952, precipitó algunos cambios al complejo escultórico, que pasaría a denominarse Monumento a Eva Perón, por destinarse no solo a glorificar la figura de la fallecida primera dama, sino también a contener sus restos. Así, el conjunto incorporaría una inmensa galería interna que funcionaría como mausoleo, incluyendo además un museo y una biblioteca que podrían visitar los "trabajadores peronistas". Precedida por unas imponentes puertas de bronce, decoradas también con bajorrelieves alusivos, la cripta, con "pavimento y columnas de granito rojo" y una gran "escalera helicoidal"8 que invitaría a su acceso, estaría ocupada principalmente por un sarcófago de plata, que se abriría en ceremonias especiales para que aquellos visitantes pudieran venerar el cadáver embalsamado de su líder. ${ }^{9}$

Esta presencia constante del "pueblo" en las descripciones del monumento se reitera en las explicaciones sobre el uso que pensaba darse al conjunto escultórico, que, tal como define Broncano (2008, p. 27), es uno de los "contextos" (junto con el diseño y la estructura) que "por la convergencia contingente en un sistema de prácticas" producen "el sentido de un artefacto". Además de los espacios ya mencionados, la cabeza del descamisado y el yunque que se ubicaría detrás de él para reforzar su potencia funcionarían respectivamente como mirador y terrazas, con vistas panorámicas de la ciudad, a los que se iba a acceder a través de catorce ascensores, que muestran el caudal de usuarios esperado. La ubicación del monumento también denota su ambición de ocupar espacios antes negados a los trabajadores. En pleno barrio de Recoleta, sobre la avenida Figueroa Alcorta, en su cruce con la calle Austria, donde actualmente se ubica la llamada Floralis Genérica, el conjunto se alzaría a la vista de todos y podría ser observado desde distintos puntos de la ciudad, por su gran altura (Figura 3). ${ }^{10}$

\footnotetext{
${ }^{7}$ Idem.

${ }^{8}$ Descripción detallada en el folleto Monumento a Eva Perón, Buenos Aires, Secretaría de Prensa y Difusión de la Presidencia de la Nación, 1955.

9 Este "uso ritual" puede emparentarse con el referido por DeMarrais, Castillo y Earle (1996), en su estudio sobre la materialización de la ideología. Estos autores afirman que "monuments may also serve as facilities or settings for ritual events". Sin embargo, el libre acceso propuesto por el peronismo no se vincula con el sugerido en ese texto: "by exercising ownership of public facilities, elites can further restrict their use and closely monitor the staging of ceremonies" (p. 19).

${ }^{10}$ Sobre la ubicación del monumento, Ballent (2009, p. 177) afirma que "constituía un aspecto central de la obra, no sólo porque dominaba la perspectiva de la ciudad desde el río, sino por su contigüidad con la residencia presidencial (...) [ya que] se preveía el desvío de la Avenida del Libertador para que [ambos] ocuparan un mismo predio". Además, la autora interpreta una particular finalidad en este rasgo, cuando asegura que "esta vinculación
} 


\section{Figura 3. Monumento al Descamisado (representación según su proyección inicial)}

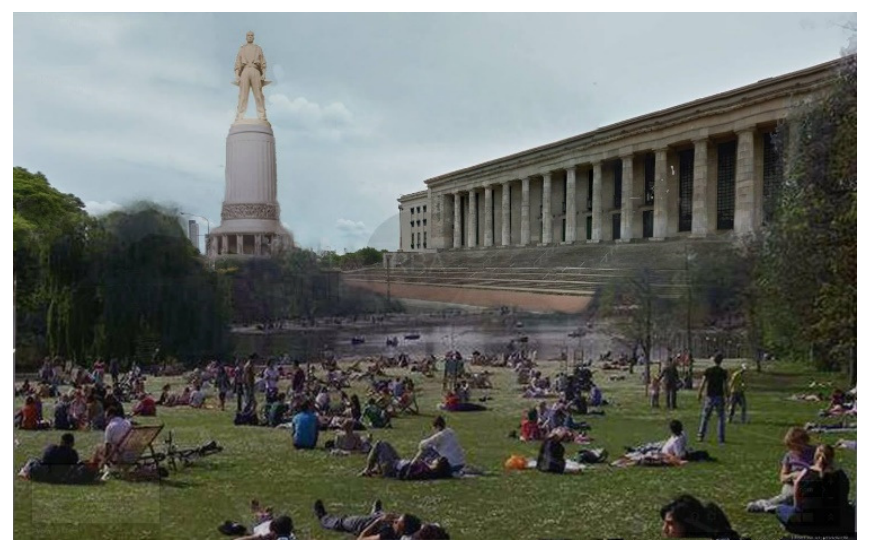

Fuente: https://tn.com.ar/sociedad/buenos-aires-en-un-streetview-del-pasado_770019

(Fecha de consulta: 1 de abril de 2019)

En un artículo publicado por la revista Mundo Peronista, en abril de 1952, el periodista Eneo resume la opinión de un presunto trabajador sobre cómo eran, antes del gobierno de Perón, los monumentos de "su" ciudad:

¡Todos coincidían en que los monumentos que adornan la ciudad que hoy es de ellos, del pueblo, eran ignorados por ellos! - Naturalmente -dice un transeúnte (...)- ¡si este es un paseo de la vieja oligarquía, felizmente desaparecida gracias a la acción del General Perón! (...) Artística y ornamentalmente el Pueblo está ausente de estos paseos. Y es muy natural, porque siempre hemos estado ausentes en la atención y en la mente de la oligarquía (...). Seguimos andando por los paseos de Palermo. Un muchacho (...) contempla una estatua de bronce [que] representa a un sembrador en momentos de arrojar las semillas (...) - Esta es otra «creación» de los artistas que no conocen el campo, ni el Pueblo, y que viven del halago de la oligarquía -nos dice (...)- Los campesinos de la época de la oligarquía pasaban hambre y vivían miserablemente. No tenían en su mirada esta olímpica adoración eglógica... ${ }^{11}$

Efectivamente, este Monumento al Descamisado, luego dedicado a Eva Perón, pretendía representar de manera auténtica al "pueblo", al trabajador argentino, al obrero peronista, que para el movimiento eran la misma cosa. Tal como afirman Carreras Monfort y Nadal Lorenzo (2002-2003, p. 68), "conjuntamente con los diversos poderes de una sociedad, se asigna un conjunto de edificios distintivos con sus propios objetos simbólicos". El peronismo erigió numerosos "edificios distintivos", que, junto con una poderosa y fecunda propaganda gráfica concentrada en lo visual, reforzaban y ampliaban los significados de sí mismo que buscaba transmitir. Del mismo modo, y siguiendo a DeMarrais, Castillo y Earle (1996), en su

estrecha impedía pensar en otro ocupante de la residencia presidencial que no fuera Perón: la operación destinada centralmente a inmortalizar a un líder muerto terminaba reafirmando el poder de un líder vivo".

${ }^{11}$ Mundo Peronista, nro. 18, 1 de abril de 1952, p. 16. 
196 | Cuando el mármol vive... La potencia peronista en un recorrido...

interpretación sobre la materialización de la ideología, ${ }^{12}$ eran Perón y Eva los que, como líderes de aquella masa, se multiplicaban y agigantaban en esos diversos mensajes. Estos sentidos incorporados a los monumentos, construcciones e incluso instalaciones efímeras erigidas por el peronismo pueden asociarse a la "cadena conceptual" a la que hacen referencia CobasFernández y Prieto Martínez (2001), como parte fundamental de la cadena tecnológicaoperativa. Las autoras afirman que esa instancia implica "una intención social, integrada en una práctica discursiva concreta, que está relacionada con la manera de hacer de un grupo social dado, y que (...) permite reconocerlo dentro de un marco social más amplio que indicará la identidad de estilo". Efectivamente, el peronismo adquirió cierta estética propia para representar a sus líderes y a los trabajadores que consideraba "peronistas" (obreros, peones rurales, enfermeras, entre otros). En el caso de las esculturas analizadas, este estilo se reconoce no solamente en los rasgos físicos de las figuras de Perón y de Eva, sino, sobre todo, en los gestos que se le atribuyen (protección, cuidado, fortaleza, sacrificio). Del mismo modo, las autoras continúan la definición explicando que "es la voluntad de saber-poder de cada grupo (...) la que marcará el tipo de uso social al que irá destinado el producto" (Cobas-Fernández y Prieto Martínez, 2001, pp. 16-17). Nuevamente, lo que se revela "conceptualmente" en el Monumento al Descamisado, y en estas esculturas como parte importante de ese edificio, es la intención peronista de un uso público del espacio.

Por ello, resulta evidente que, derrocado el gobierno en 1955, estos símbolos fueran las primeras y silenciosas víctimas de una eliminación que pretendió ser mucho más que material. Recientes estudios sobre los fenómenos iconoclastas, especialmente aquellos dedicados a estos procesos de destrucción desde el siglo $\mathrm{XX},{ }^{13}$ han centrado su atención en buscar explicar sus posibles razones, los motivos que los fundamentan, problematizando así el propio carácter de lo suprimido. Gamboni (2014, p. 28), por ejemplo, distingue el concepto de iconoclasia del de vandalismo, destacando que el primero se refiere a la "destrucción de cualesquiera imágenes y obras de arte y la oposición a ellas y, metafóricamente, el hecho de «atacar o derrocar instituciones veneradas y preciadas creencias, tenidas por falaces o supersticiosas»", mientras que el segundo tipo de acción se dirige únicamente a aquellos actos considerados "«bárbaro, ignorante o inartístico» desprovisto de sentido", mostrando así que "la supuesta presencia o ausencia de un motivo es hoy la razón principal para elegir uno u otro término". Freedberg (2010, p. 435), por su parte, explica que, si bien la motivación "más clara parece ser de orden político", cuyo "objetivo consiste en eliminar todo aquello que simboliza o representa el orden

\footnotetext{
12 Estos autores afirman que "materialization of ideology is (...) a strategic process in which leaders allocate resources to strengthen and legitimate institutions of elite control" (DeMarrais, Castillo y Earle, 1996, p. 16).

${ }^{13}$ Excede a los fines de este escrito recorrer las distintas interpretaciones sobre ese tema y es por ello que se retoma especialmente ese rango temporal, no solo por su pertinencia en relación al objeto de estudio aquí abordado, sino además por su disponibilidad en idioma español, debida esencialmente al interés que han suscitado para las ciencias sociales diversos acontecimientos iconoclastas recientes, como los acaecidos tras la caída del Muro de Berlín en los antiguos países de la URSS o los posteriores al 2001 en Medio Oriente. Pueden verse también Latour y Weibel (2002); Otero (2012); Boldrick, Brubaker y Clay (2013) y Freedberg (2017).
} 
antiguo", no deben dejar de considerarse los "aspectos psicológicos" (p. 437), por los que "los iconoclastas (...) [creen] que el poder de lo representado se desvanecerá al destruir o mutilar la representación" (p. 452).

Efectivamente, la autodenominada Revolución Libertadora, sobre todo durante el período encabezado por el general Pedro Eugenio Aramburu, buscó hacer desaparecer todo rastro peronista de la sociedad argentina. Para ello, decidió no solo prohibir su nombre, a través del conocido decreto $4161,{ }^{14}$ sino además llevar adelante una política sistemática de eliminación de imágenes, que incluyó quema de libros, afiches, fotografías y posters peronistas, así como también destrozo de cuadros, bustos y esculturas representativos de aquel movimiento. Y si bien el Monumento a Eva Perón nunca llegó a erigirse completamente, ${ }^{15}$ las seis esculturas que lograron terminarse en los talleres de Tommasi fueron rastreadas por distintos grupos de tareas del gobierno de facto $y$, junto a hordas de seguidores del golpe de Estado, ${ }^{16}$ decapitadas, mutiladas y arrojadas al Riachuelo, donde permanecieron casi treinta años.

\section{Recuperación (o instancia actual)}

Tal como reproduce un diario marplatense, Marcelo Padró, quien, durante 2016 y 2017 fuera director del Museo Histórico 17 de octubre, donde actualmente se encuentran las esculturas, narra que:

con el regreso de la democracia, trabajadores del ministerio de Obras Públicas que conocían su localización, se la comunicaron al por entonces intendente de Lomas de Zamora, Eduardo Duhalde, a quien le pidieron que las saque del agua (...). Estuvieron guardadas en unos almacenes hasta que, en 1996, las trasladaron a la quinta. ${ }^{17}$

\footnotetext{
${ }^{14}$ El decreto, publicado en el Boletín Oficial, el 9 de marzo de 1956, constaba de cinco artículos, que prohibían expresamente "la utilización de imágenes, símbolos, signos, expresiones significativas, doctrinas, artículos y obras artísticas, (...) que sean (...) representativas del peronismo", e incluía una lista de vocablos proscritos, tales como "peronismo", "peronista", "justicialismo", "justicialista", "tercera posición”, "el nombre propio del presidente depuesto o el de sus parientes", al igual que la Marcha peronista y los discursos del ex presidente y de Eva Perón. Además, establecía una pena de prisión de treinta días a seis años para los infractores, que adicionalmente debían pagar una multa y quedaban inhabilitados para desempeñar cargos públicos, sindicales o en partidos políticos. Información extraída del sitio web: Educ.ar. Recuperado de: https://www.educ.ar/recursos/128814/decreto-4161-deprohibicion-de-propagandaperonista (Fecha de consulta: 1/04/2019).

${ }^{15}$ El 30 de abril de 1955, cuarenta y cinco días antes de los bombardeos a Plaza de Mayo y tan solo cuatro meses y medio antes de su derrocamiento, Perón coloca la "primera cucharada de mezcla" en el sitio donde se levantaría el monumento. En esos plazos, llegaron a realizarse las fundaciones, el basamento circular y parte incipiente de la columnata, que fueron destruidas por el gobierno de facto.

${ }^{16}$ De hecho, las primeras destrucciones realizadas los días posteriores al derrocamiento de Perón, a mediados de setiembre de 1955, fueron ejecutadas de manera espontánea por individuos que, dirigiéndose a distintas dependencias públicas y unidades básicas del peronismo, se dejaban fotografiar sobre los restos destrozados de bustos y cuadros del líder y su esposa.

17 "El mausoleo a Eva Perón, una obra colosal con final violento" (24 de julio de 2017), diario La Capital, Mar del Plata. Recuperado de https://www.lacapitalmdp.com/mar-del-plata-el-mausoleo-a-eva-peron-una-obra-colosalcon-final-violento/ (Fecha de consulta: 13/03/2019). Se consultó al especialista en peronismo Roberto Baschetti y se
} 
198 | Cuando el mármol vive... La potencia peronista en un recorrido...

Así, ese contexto de hallazgo de las esculturas permitió explicar su violento descarte, así como también el estado en el que fueron encontradas mostró los destrozos previos (Figura 4). Que las figuras de Perón y de Eva fueran los únicos objetivos y su decapitación el principal daño realizado, direcciona las interpretaciones de su destrucción hacia aquellas motivaciones políticas también imbuidas de aspectos psicológicos, en las que "los iconoclastas contemplan una imagen, que para ellos representa un cuerpo (...); lo perciben como algo viviente o lo tratan como algo viviente" (Freedberg, 2010, p. 452), siendo así su ataque indirectamente dirigido a quienes son allí presentados.

Figura 4

Esculturas originales en el taller del artista Leone Tommasi y su estado actual
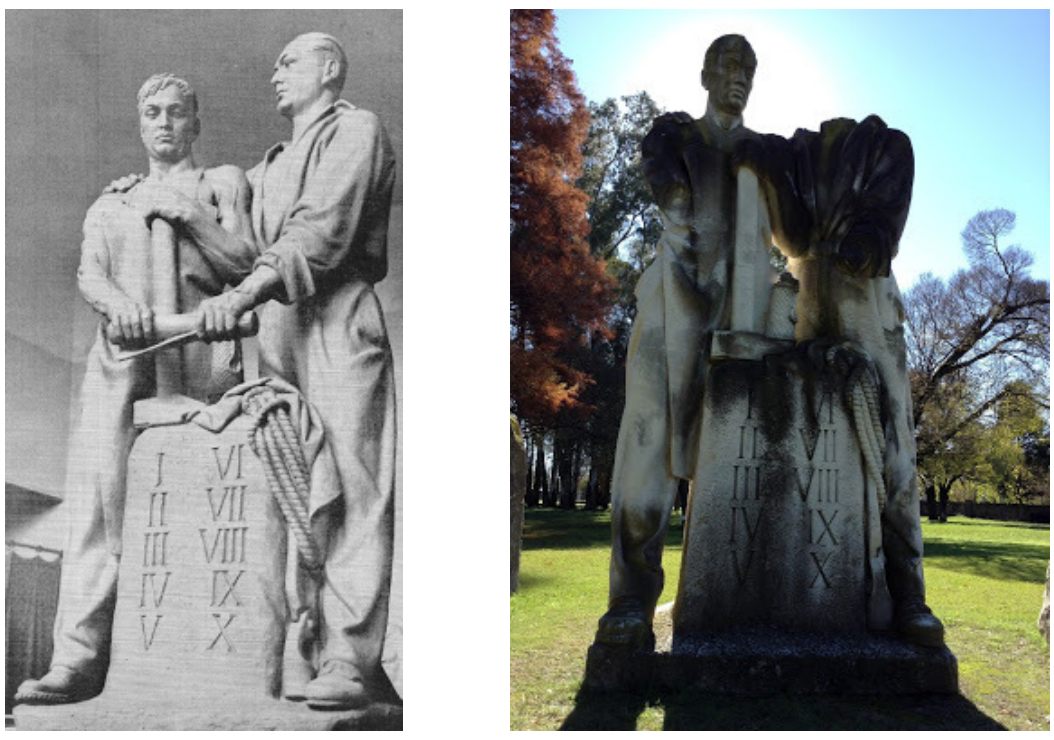

estudiaron diarios y revistas de aquellos años, pero aun así no pudieron hallarse otras fuentes que constaten o refuten esa narración. 

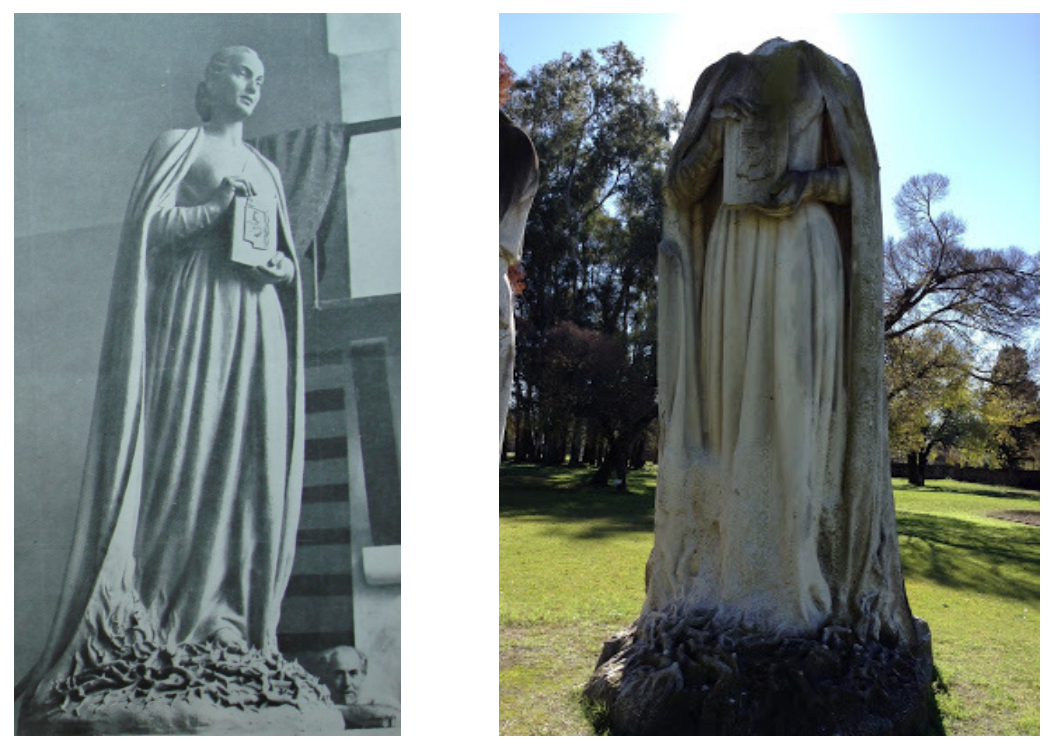

Fuente: http://viajealasestatuas.blogspot.com.ar/p/estudio-preliminar-por-oscarandresde.html (Fecha de consulta: 20/04/2019)

Los derechos del trabajador y La razón de mi vida llegaron entonces al museo para convertirse en parte de su patrimonio, tras la donación realizada por el Gobierno de la Provincia de Buenos Aires. Siguiendo a Pérez de Micou (1998), se trataría, por lo tanto, de una colección sistemática, porque posee una "coherencia interna" que "responde a un tema central", el peronismo clásico, y pasiva, al menos en este caso, ya que se trató de un "regalo" en el que no medió la "elección del museo". Del mismo modo, el rol de la institución toma preponderancia en el recorrido biográfico de las esculturas por dos motivos, vinculados ambos a aquello que la autora refiere como "segundo momento" de la historia de las colecciones, esto es, "las actividades dentro del museo" (Pérez Micou, 1998, p. 226).

En primer lugar, la institución influye al aceptar aquella donación y decidir exhibir las esculturas en el parque que rodea la quinta. El Museo Histórico 17 de octubre recibe a sus visitantes con un cartel que advierte: “Usted se encuentra en la casa de Perón y Evita. Aquí se gestó la Revolución Nacional Justicialista". Efectivamente, la Quinta San Vicente fue el lugar de descanso del matrimonio Perón, entre los años 1946 y 1952. Además de aquel inmenso parque de 19 hectáreas, donde más de ochenta especies de árboles comparten escena con escudos de todas las provincias argentinas, elementos característicos de cada región y, por supuesto, las esculturas, el predio comprende actualmente distintas construcciones. Existe la llamada "casa principal", que es un chalet de estilo clásico, de piedra Mar del Plata y mampostería de madera, construido en 1947 (y remodelado por el entonces presidente en 1973), donde hoy se exhiben fotografías de ambos, condecoraciones que recibieron y distintos objetos personales, tales como uniformes, muebles, libros y documentos. Además, pueden visitarse "el Torreón", que es una torre de agua, en la cual una escalera caracol conduce hasta 
200 | Cuando el mármol vive... La potencia peronista en un recorrido...

la parte superior donde se grababan los discursos presidenciales que luego se transmitían en cadena nacional, y la nombrada "Plaza del Abrazo", cuya denominación proviene de la imagen grabada en un muro que representa el abrazo entre Eva y Perón en el balcón de la Casa Rosada, el 17 de octubre de 1951. A pocos metros de allí, se encuentra una réplica de una estación de trenes, levantada para proteger el tren presidencial de trocha angosta que usaron distintos mandatarios argentinos, desde Yrigoyen hasta Alfonsín, del que se conservan tres vagones (el comedor, el dormitorio y el furgón), revestidos en petiribí lustrado y decorados con vitrales y otros detalles, como el escudo nacional grabado en cada una de las manijas de las puertas. Dentro de la quinta, también se encuentra un mausoleo que conserva, desde el año 2006, los restos de Perón..$^{18}$ Finalmente, un edificio moderno, inaugurado en 2002, contiene un amplio auditorio, las áreas administrativas del museo, una cafetería para los visitantes y tres salas de exposición temporaria, además de la exhibición principal, en la que, mediante gigantografías, paneles tridimensionales y numerosa iconografía de la época, se presentan los pilares del primer gobierno peronista, en torno a los ejes de Independencia Económica, Soberanía Política y Justicia Social. Sin embargo, en todo este recorrido, las esculturas Los derechos del trabajador y La razón de mi vida no están incorporadas activamente al guion museológico (Figura 5), ya que los antiguos carteles que se ubicaban a su alrededor y que narraban escuetamente su historia fueron retirados recientemente, pudiendo el visitante únicamente conocerla si participa de la visita guiada (Figura 6).

\footnotetext{
${ }^{18}$ El 17 de octubre del año 2006 los restos del ex presidente Perón fueron trasladados, desde el cementerio de la Chacarita, a su nuevo mausoleo en San Vicente, donde se produjeron ciertos incidentes. El diario Página/12 explica que los enfrentamientos "tuvieron como protagonistas a los afiliados de los gremios de la construcción y de camioneros, quienes pugnaban por una posición privilegiada frente al escenario (...). Entre los seguidores de Hugo Moyano que habían sido desplazados (...) apareció un hombre con un revólver, apuntó y disparó varios tiros (...). Lo identificaron como Emilio Miguel Quiroz, custodio y chofer de Pablo Moyano, el hijo del titular de la CGT. La policía informó que no hubo ningún herido de arma de fuego": "El homenaje que derivó en desastre" (18 de octubre de 2006), diario Página/12. Recuperado de https://www.pagina12.com.ar/diario/elpais/1-74675-2006-10-18.html (Fecha de consulta: 13/03/2019).
} 
Figura 5.

Mapa del Museo Histórico 17 de octubre

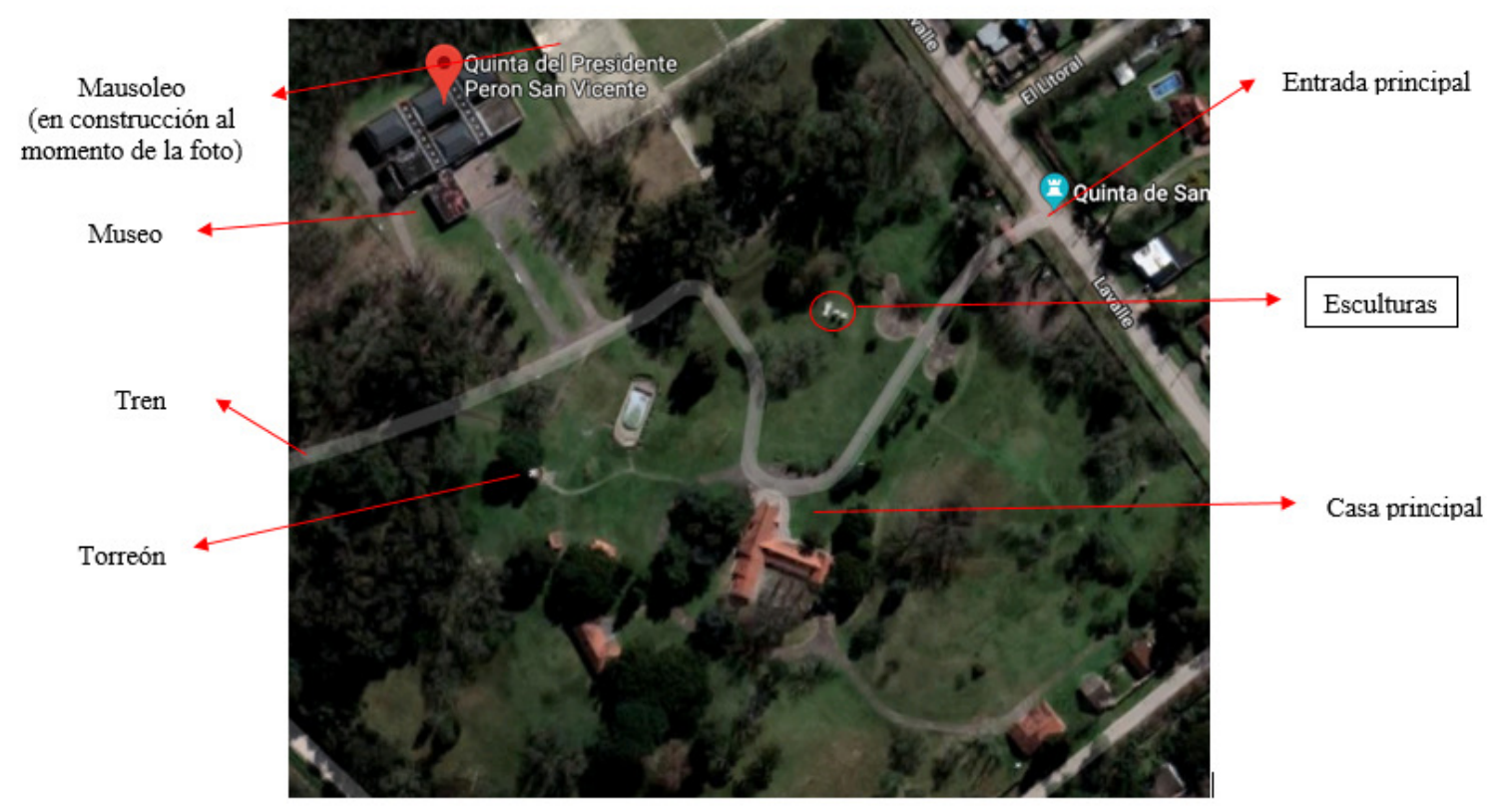

Fuente: Elaboración propia

Figura 6. Antiguos carteles de referencia de las esculturas Los derechos del trabajador y La razón de mi vida, hoy ausentes en el Museo
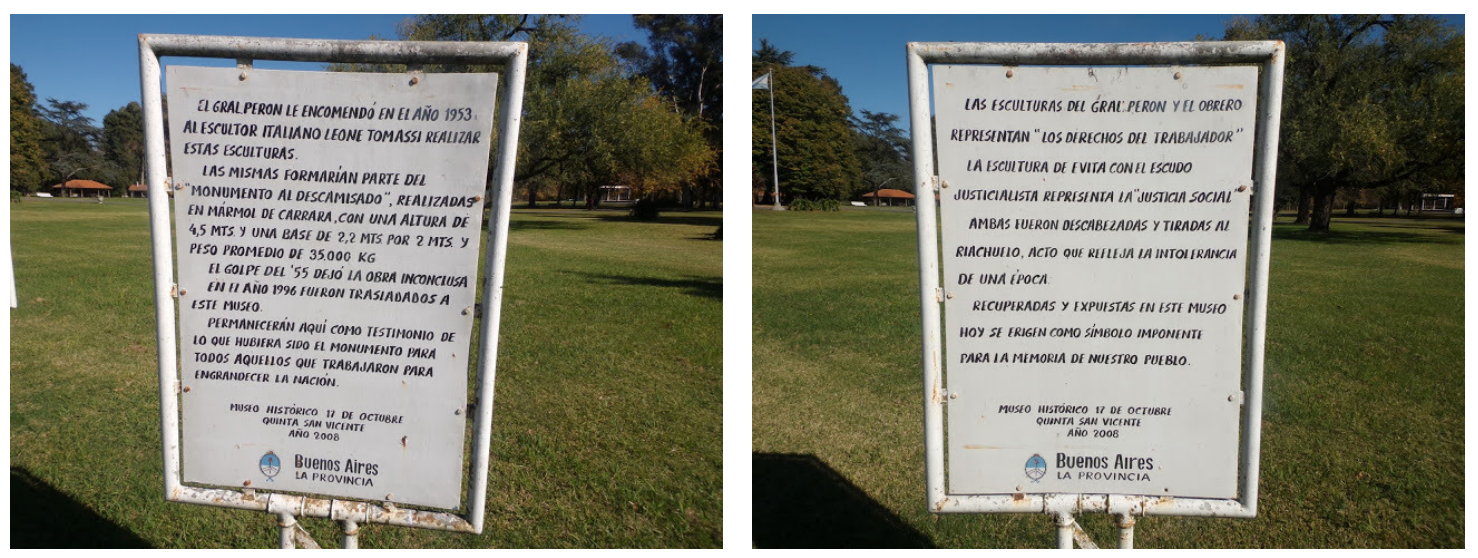

Fuente: https://historiasconpueblos.blogspot.com/2017/05/los-restos-del-monumento-aldescamisado.html (Fecha de consulta: 13/05/2019)

En segundo lugar, el museo también se vuelve protagonista en la historia de estas esculturas porque, al recibirlas, toma la decisión de conservarlas tal como fueron halladas, como explica el antiguo director del espacio: "El hijo de Tommasi se ofreció años más tarde a reparar las piezas vandalizadas, pero le dijeron que las dejara así, para que quedara registro 
202 | Cuando el mármol vive... La potencia peronista en un recorrido...

del tremendo odio que motivó su destrucción en ese momento". ${ }^{19}$ Es así como, con esta decisión, se intenta reforzar la idea de que "human and object histories inform each other", tal como afirman Gosden y Marshall (1999, p. 169). Al preservar la mutilación de las esculturas, se buscó que estos objetos, así como fueron "transformados por personas", en los términos expuestos por aquellos autores, lograran también, de algún modo, "transformar a" los visitantes, produciendo un impacto difícil de generar únicamente desde el relato oral o fotográfico y que el contacto directo y la experiencia de ese encuentro pueden grabar en la memoria. Se construye así una biografía de tipo social, que, tal como describe Kopytoff (1991, p. 94), "concibe el objeto como una entidad culturalmente construida, cargada de significados culturalmente especificados, y clasificada y reclasificada de acuerdo con categorías culturalmente constituidas". Al dejar las huellas de una parte de la historia de las esculturas, se muestran las ausencias, para que ellas hagan recordar. Y se reafirma el carácter semióforo de esos objetos, en términos de Pomian (2007, pp. 131-133), cuando se conservan en ellos las distintas "funciones" por las que se vieron atravesados, sin dejar de lado su actual "función" de memoria social. ${ }^{20}$

\section{Reapropiación}

Carreras Monfort y Nadal Lorenzo (2002-2003, p. 78) afirman que "la última etapa de un objeto se puede considerar que es el momento en que pasa a formar parte del patrimonio cultural, histórico o arquitectónico de una sociedad". Sin embargo, las esculturas Los derechos del trabajador y La razón de mi vida parecen resurgir una y otra vez, resistiendo los entierros forzados y los encierros institucionales.

El fotógrafo Santiago Porter conocía la historia del fallido Monumento al Descamisado y también que parte del mismo había sido rescatado, pero no tenía noción del lugar donde se encontraban esos restos devueltos a la luz. En una entrevista, cuenta:

Finalmente, tuve la posibilidad de verlas el día del traslado de los restos de Perón a la quinta en San Vicente, cuando se enfrentan muchachos de la UOCRA con camioneros de Moyano, entre los palazos y los tiros de «Madonna» Quirós, en uno de los paneos de la cámara de Crónica, veo la escultura y digo: «Puta, es ésa la escultura que yo estaba buscando». ${ }^{21}$

\footnotetext{
${ }^{19}$ Idem.

${ }^{20}$ Un recorrido similar es descripto por Rambelli y Reinders (2013) para una estatua de Buda del año 678 d.C., robada, ultrajada y hasta desaparecida durante siglos, para ser finalmente rescatada en 1937, declarada tesoro nacional y exhibida como parte de la colección de un museo en Nara, Japón. Remarcando que "the history of an icon includes repeated and overlapping moments of contestation, appropriation, damage, restoration, and amnesia" (p. 40), los autores definen como "negative cultural redefinition or even iconoclastic preservation" (p. 46) a la acción y función de los museos al recuperar esos objetos manteniendo los rastros de aquellos procesos previos de destrucción.

${ }^{21}$ Hoy hay foto (productor). (2014). Entrevista a Santiago Porter. Recuperado de https://vimeo.com/84578363.
} 
Fue así como, en el año 2008, luego de varios meses intentando conseguir los permisos pertinentes y urgido por el temor de una nueva destrucción, el artista decidió recapturarlas, otorgando a las esculturas nuevos sentidos, a partir de distintos recursos del ámbito fotográfico, como el título de la obra, su encuadre y la propia composición de la imagen (Figura 7). Exhibida en decenas de muestras individuales y colectivas en distintas ciudades de Argentina, Chile, Brasil, México, Estados Unidos, Francia y Alemania, le ha valido a su autor, junto con el resto de su producción, amplia fama internacional, no solo por su calidad artística, sino también por la significación que ella parece imprimir al complejo movimiento peronista.

\section{Figura 7.}

\section{"Evita"}

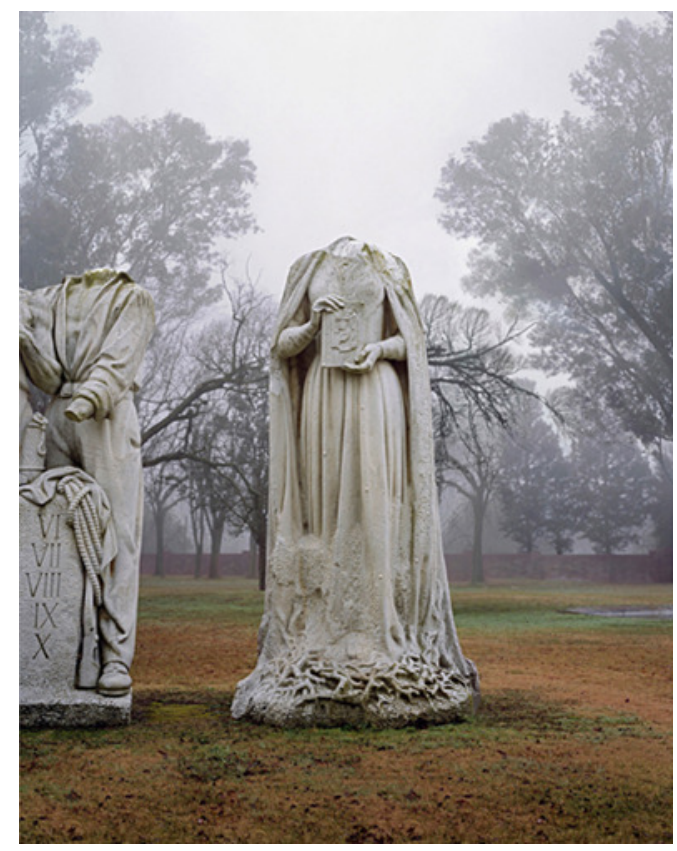

Fuente: http://santiagoporter.com/uploads/portfolio/b96f1b4ad1549a79b3ef5c0e2840be00.jpg

(Fecha de consulta: 10/04/2019)

La fotografía Evita es una impresión inkjet sobre papel de algodón Hahnemühle FineArt, de 1,74 metros de alto y 1,40 de ancho. Porter la describe diciendo:

En esta foto, lo que vemos, es una escultura de Evita, decapitada, y, a la derecha de esta escultura, se ve un segundo cuerpo, que es el cuerpo de Perón, al cual le faltan las manos y la cabeza.22

${ }^{22}$ Idem. 
204 | Cuando el mármol vive... La potencia peronista en un recorrido...

Efectivamente, el encuadre de la imagen excluye de la escena al trabajador sobre el que el líder apoya su brazo derecho y deja únicamente a la pareja como protagonista. Es la escultura de Eva, sin embargo, el centro absoluto del recorte y, de allí, el propio título de la obra, para el que, además, se elige el popular diminutivo. Para Porter, entonces, no solo parecen ser Perón y su esposa el centro exclusivo del amplio movimiento que gestaron, sino también las únicas víctimas del odio antiperonista. Vuelve a borrarse de la historia aquel "pueblo" que el propio monumento del que provienen las esculturas buscaba homenajear.

Respecto del tipo de luz y del ambiente generado para la fotografía, vale decir que la obra forma parte de su serie Bruma, ${ }^{23}$ en la que, según sus propias palabras, Porter busca retratar, en imágenes de gran tamaño, "a la Argentina o a la posible relación entre el aspecto de las cosas y su historia". En la primera etapa, desarrollada durante el año 2007, el artista trabaja específicamente sobre la apariencia de determinados edificios públicos de la ciudad de Buenos Aires, construidos entre finales de la década del '30 y principios de la del '50. Pensándolos como rostros, retrata sus frentes, queriendo evidenciar "las distintas capas de historia acumuladas en esa arquitectura deteriorada". La segunda etapa de la serie, que se extiende entre 2008 y 2011, y de la que Evita forma parte, "responde a cierta idea de cómo muchos monumentos creados con el fin de conmemorar eventos específicos terminan resultando obsoletos" y está protagonizada por diferentes estructuras, elegidas por "las anécdotas que se esconden detrás (...) y fundamentalmente por la capacidad [de] estos objetos para evocarlas: torres de vigilancia, (...) paredones de fusilamiento, esculturas decapitadas, puentes que no conectan nada, entre otros". Por su parte, la última etapa de la serie, aún en proceso, busca "fotografiar lugares específicos donde la fisonomía (...) se ha[ya] visto modificada tanto por decisiones políticas como por el propio peso de la historia", siendo los paisajes elegidos bosques secos, basurales o sitios abandonados. ${ }^{24}$

Las ideas de deterioro, obsolescencia e inutilidad, parecen ser, entonces, las que recorren la serie, donde las nieblas remiten a un pasado muerto, que solo vuelve de manera fantasmal. Así, aquel rescate visual, que pretendía salvar del olvido a estas esculturas ante una inminente repetición de su primera destrucción, esta vez en manos de los propios seguidores peronistas, produce una imagen que recaptura a ese movimiento político, reduciendo su fuerza y alcances sociales.

\section{Conclusión}

El recorrido biográfico aquí transitado buscó demostrar cómo, en las esculturas Los derechos del trabajador y La razón de mi vida, que formaron parte del llamado Monumento al Descamisado, se condensan ciertos rasgos de una potencia propia del movimiento político-cultural peronista,

\footnotetext{
${ }^{23}$ Esta serie fue publicada además en formato libro: Porter (2017).

${ }^{24}$ Todas las citas fueron extraídas del sitio web del artista. Recuperado de: http://www.santiagoporter.com/home (Fecha de consulta: 20/03/2019).
} 
que parece retornar una y otra vez más allá de los reiterados intentos por ser contenida. Aristóteles define a la potencia (dýnamis) en oposición, pero a la vez estrechamente ligada, al acto (enêrgeia), es decir, como una fuerza en suspenso, como posibilidad, "como [un] combustible [que] no se enciende por sí, sin un principio de combustión" (citado en Agamben, 2007, p. 353). Y es precisamente esa dinámica de acciones y pausas, de destellos y oscuridades, la que se reflejó en las distintas etapas biográficas analizadas, entre las que podrían incorporarse incluso las indagaciones de estas líneas, motivadas por esa misma potencia.

Ya desde sus orígenes como idea, el monumento concentraba en sí mismo distintas pretensiones del peronismo, vinculadas a la totalidad armónica, la desmesura, el carácter de lo estatal o la vocación pedagógica. Aunaba la (breve) historia del movimiento, encabezada por sus dos líderes y protagonizada por los trabajadores, con la de la propia nación que afirmaba estar transformando; las reunía en un único espacio, colosalmente emplazado en un sitio ineludible a la vista; lo convertía en un ámbito abierto, público, para ser usado y recorrido; y lo volvía narrable, al definir y presentar en él, de un modo didáctico, sus principales pilares. Son precisamente estos rasgos del monumento los que parecen resultar incomprensibles, al punto de no poder recuperarlo como parte importante de un posible relato del movimiento, e incluso intolerables, para los que debieron decapitar sus efigies antes de ahogarlas y enterrarlas en el lecho del río, o para quien las recaptura, abrumándolas.

Bataille (2008, p. 70) afirma que "cuando un nativo de Costa de Marfil mete unas hachas de piedra pulida de la época neolítica dentro de un recipiente lleno de agua, se baña en el recipiente y ofrenda unas gallinas a lo que cree que son piedras de trueno (caídas del cielo en un rayo), no hace sino prefigurar la actitud de entusiasmo y de comunión profunda con los objetos que caracteriza al visitante del museo moderno". A esta comunión parecen temerle quienes poseen (o buscan poseer, por medio de la fotografía) a las esculturas Los derechos del trabajador y La razón de mi vida. El papel activo en las relaciones sociales que estos objetos pudieron haber tenido al momento de su creación (de haberse concretado el proyecto del monumento) resulta contenido en este presente histórico, limitando así una comprensión cabal de aquellos años. Y pensando en el rol que actualmente pueden construir los museos como espacios creativos y críticos, debe considerarse también que, en las capas de significados que las esculturas acumulan, se conservan seguramente otras historias que deben recuperarse y volverse aún más visibles, no solo para permitir nuevos sentidos e incluso usos singulares de esos objetos, sino, sobre todo, para que la práctica museológica sea el fuego que active su potencia.

\section{Referencias bibliográficas}

Agamben, G. (2007). La potencia del pensamiento. Buenos Aires: Adriana Hidalgo.

Ballent, A. (2009). Las huellas de la política: vivienda, ciudad, peronismo en Buenos Aires, 1943-1955.

Bernal: Universidad Nacional de Quilmes - Prometeo.

Bataille, G. (2008). La conjuración sagrada. Ensayos 1929-1939. Buenos Aires: Adriana Hidalgo. 
206 | Cuando el mármol vive... La potencia peronista en un recorrido...

Boldrick, S., Brubaker, L. y Clay, R. (Eds.) (2013). Striking images, Iconoclasms Past and Present. Farnham: Ashgate Press.

Broncano, F. (2008). «In media res»: cultura material y artefactos. ArtefaCToS, 1 (1), 18-32.

Carreras Monfort, C. y Nadal Lorenzo, J. (2002-2003). Reflexiones en torno a la cultura material. Nuevas aproximaciones. Pyrenae, 33-34, 65-80.

Cobas-Fernández, I. y Prieto Martínez, M. P. (2001). La cadena tecnológica operativa como una herramienta teórica y metodológica. Una perspectiva desde los planteamientos de la arqueología del paisaje. Cuadernos de Estudios Gallegos, XLVIII (114), 9-27.

Criado Boado, F. (2012). Arqueológicas. La razón perdida. La construcción de la inteligencia arqueológica. Barcelona: Editorial Bellaterra.

DeMarrais, E., Castillo, L. J. y Earle, T. (1996). Ideology, materialization and power strategies. Current Anthropology, 37 (1), 15-31 y 47-86.

Freedberg, D. (2010). El poder de las imágenes: estudios sobre la historia y la teoría de la respuesta. Madrid: Ediciones Cátedra.

Freedberg, D. (2017). Iconoclasia: historia y psicología de la violencia contra las imágenes. Buenos Aires: Sans Soleil Ediciones.

Gamboni, D. (2014). La destrucción del arte. Iconoclasia y vandalismo desde la Revolución Francesa. Madrid: Ediciones Cátedra.

Gené, M. (2008). Un mundo feliz. Imágenes de los trabajadores en el primer peronismo (1946-1955). Buenos Aires: Fondo de Cultura Económica - Universidad de San Andrés.

Gosden, C. y Marshall, Y. (1999). The cultural biography of objects. World Archaeology, 31 (2), 169-178.

Ingold, T. (2013). Los materiales contra la materialidad. Papeles de Trabajo, 7 (11), 19-39.

Kopytoff, I. (1991). La biografía cultural de las cosas: La mercantilización como proceso. En A. Appadurai (Ed.), La vida social de las cosas: perspectiva cultural de las mercancías (pp. 89-124). México DF: Editorial Grijalbo.

Latour, B. y Weibel, P. (Eds.) (2002). Iconoclash: Beyond the Image Wars in Science, Religion and Art. Cambridge (Ma.): MIT Press.

Moreyra, C. (2011). Pensar los objetos. Problemas y fuentes para el estudio de la cultura material en la época colonial. Anuario de Arqueología, 3 (3), 121-141.

Otero, C. (Ed.) (2012). Iconoclastia. La ambivalencia de la mirada. Madrid: La Oficina de Arte y Ediciones.

Pérez de Micou, C. (1998). Las colecciones arqueológicas y la investigación. Revista do Museu de Arqueologia e Etnologia, 8, 223-233.

Pomian, K. (2007). Historia cultural, historia de los semióforos. En Sobre la historia (pp. 125147). Madrid: Ediciones Cátedra.

Porter, S. (2017). Bruma. Buenos Aires: Ediciones Larivière.

Rambelli, F. y Reinders, E. (2013). The Buddha head at Köfukuji Temple (Nara, Japan). En S. Boldrick, L. Brubaker y R. Clay (Eds.), Striking images, iconoclasms past and present (pp. 3946). Farnham: Ashgate Press.

Renfrew, C. y Bahn, P. (1993). Arqueología. Teorías, métodos y práctica. Madrid: Editorial Akal.

Schiffer, M. (1990). Contexto arqueológico y contexto sistémico. Boletín de Antropología Americana, 22, 81-93.

Anuario de la Escuela de Historia Virtual - Año 11 - Nº 18 - 2020: pp. 188-207. ISSN: 1853-7049 
207 | María Florencia Reyes Santiago

Para citar este artículo:

Reyes Santiago, María Florencia (2020). Cuando el mármol vive... La potencia peronista en un recorrido biográfico de las esculturas del Monumento al Descamisado. Anuario de la Escuela de Historia Virtual, 18, 188-207. 